\title{
The Ten Principles of Socially Responsible Digital Health Design
}

\author{
Emmanuel Tsekleves ${ }^{{ }^{*}}$, Rachel Cooper \\ ImaginationLancaster, LICA, Lancaster University, UK \\ *Corresponding author e-mail: e.tsekleves@lancaster.ac.uk
}

\begin{abstract}
:
We are now, more than ever, aware of the social challenges that face us globally, keeping healthy is at the top of the list. Increasingly in the last ten years, designers have turned their attention not just to designing to alleviate and prevent illness but designing specifically to increase individual and community wellness and health. Digital health design has been one of those dimensions adopted to address the challenge. In this opinion piece we posit that in the domain of digital health all design should be socially responsible in order for us to consider it good design. Drawing on the history of socially responsible design and the emergence of digital health applications we propose Ten Principles of Socially Responsible Digital Health Design.
\end{abstract}

Keywords: Responsible design; digital health; good design; responsible innovation

\section{Background}

\subsection{Evolution of Design and Social Responsibility}

Social responsibility amongst designers is not new and has appeared intermittently since the industrial revolution, epitomised by people such as William Morris in his move against mass manufacturing and towards the inclusion of human values in production. However commercial and technological forces dominated the 20th century, and yet over the past half century, design as a discipline has changed profoundly, as has the design profession. The profession of design in the 20th century was indeed, in the main, considered an agent of industry, designers focused on products for manufacturing or services to advertising and new product development and innovation. For example, design's contribution to productivity and sales. However, alongside this focus was the age of activism that began in the 1960's and 70's, this brought with it an increasing awareness amongst the design profession of their role in campaigns such against:

"the nuclear bomb (Campaign for Nuclear Disarmament) or activism related to the environment (Friends of the Earth, Greenpeace), feminism and equality (Women's Liberation Movement, Civil Rights movement) and the early concerns around disability, aging and social 
inequity epitomised perhaps by the iconic project of the hospital bed (one of the first to undertake formal design in the hospital environment) funded by the Kings Fund" (Cooper, 2019, p6).

Buckminster Fuller, set out in 1963, a proposal for a comprehensive anticipatory design science whereby he proposed, "dedicating at least its next ten years to making the total worlds resources serve 100 percent of humanity at higher standards of living than hitherto experienced by any men" (Buckminster Fuller, 1963, p2). It did not happen, due to the rise in consumerism of the 1980s that dominated the landscape for design; whereby the design of products and service for global consumption was the predominant paradigm. However, another prod in the direction of responsibility was in the work of Victor Papanek in the publication of Design for the Real World (1971). A very controversial book at the time, but it presented a benchmark statement for the role of design, that designers should design for everyone, the able and disabled, that design should consider the environment and the finite resources of the earth, he illustrated the ethical aspect of design. Work in other spheres, such as Germaine Greer's The Female Eunuch (1970) which encouraged women to look at the way in which they were treated both in the workplace and the home, and Schumacher's Small is Beautiful (1973), which considered the unsustainable approach to economies, the use of natural resources and the human impact of technology set the scene for a transition in how designers saw their role in society (Cooper, 2019). These and the many other socially or environmental movements informed the foundations of what we might now call responsible design (Cooper, 2019).

Whilst one might cynically view designers of having jumped on the bandwagon of corporate social responsibility especially towards the end of the 1990's (Cooper, 2005). Over the past thirty years designers and design researchers have increasingly began to consider the wider implications of design. Designers began to recognise how what they designed could bring harm to people and the planet, thus design's social and moral responsibility becomes a discussion point. Alongside this heightened awareness of the role of design, the context in which we design and what is designed has changed rapidly. No longer is it products and material goods, designers design services and along the way the recognition that the user is central to the process, the rise in user centred design, in codesign and participatory design has broadened the responsibility of the design team to include all stakeholders. Whilst internationalisation and globalisation has raised understanding of people in all countries, how they work (i.e. slave labour, child labour), levels of poverty, levels of resource use (Brazilian rainforests and sustainable food sources) and more. Design has to consider social, environmental as well as economic factors in the creative process of creating all products and services (Tsekleves et al, 2021). At the same time that design and designing has transitioned from designing the material to the immaterial world it has embraced the opportunities of the digital world and the technologies that support it. So not only has design had to extend its scope in the social context (Chen et al 2016), it has had to extend its scope in the environment as well as continuing to deliver the bottom line for companies.

This extension of scope and of recognition of design responsibility, suggests that designers must find a way of determining their position and stance on many critical issues in the arenas in which they work. If, for instance designers do have a responsibility to design products and services for the common good, then how do they go about determining the principles and values by which they should work. Unlike the medical profession designers do not have any form of ethical oath, such as the principle of Non-maleficence - to not be the cause of harm or to promote more good than harm (Gillon, 1994). 
In the context of health and wellbeing what is good design, and to what degree is it the responsibility of designer to promote healthy behaviours and enhance wellbeing. In Tsekleves and Cooper (2017) Book on Design for Health, and as seen on Figure 1, it is clear that designers contribute both to the determinants of health and to the systems of health support and repair. But what is the difference between good design and designers' social responsibility.

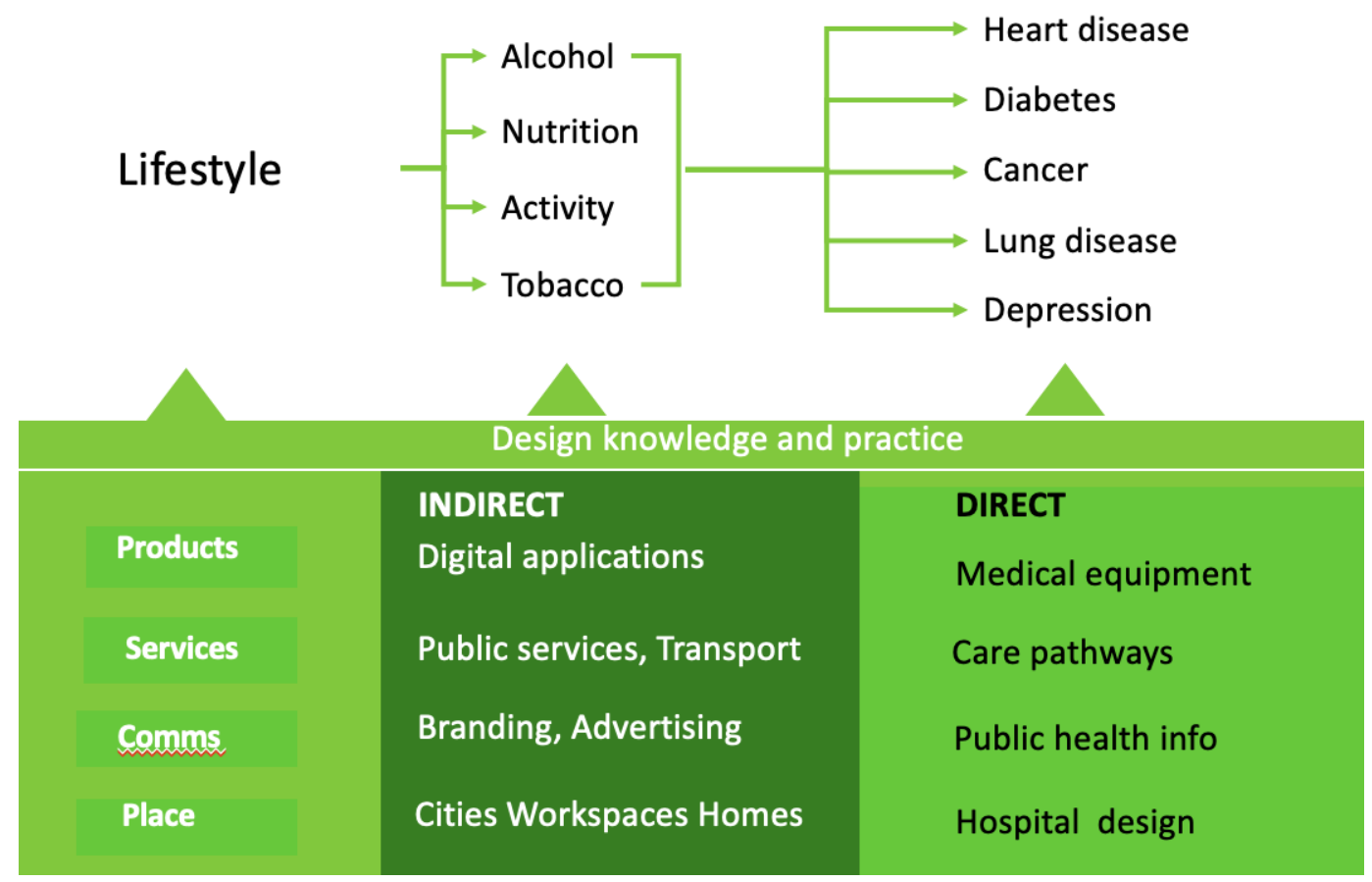

Figure: 1 How design contributes to Health (Cooper, 2011)

\subsection{Good Design and Dieter Rams}

In the late 20th century, many regarded 'good design' as effective design that increased market profits. In that context, the combination of form and function was previously viewed as good design and on that basis Dieter Rams, an architect who worked for most of his life at Braun, (latterly as chief designer until 1995) in 1970's formed Ten principles of Good Design, that have been a classical reference for designers, especially product designers (Rams, 2009). These principles by Rams (2009) are that Good Design:

1. "is innovative

2. makes a product useful

3. aesthetic

4. makes a product understandable

5. is unobtrusive

6 . is honest

7. is long-lasting

8. is thorough, down to the last detail

9. is environmentally-friendly

10.is as little design as possible".

It can be noted that Rams, like Papanek (1971), incorporated issues of environmental and social responsibility. Thus, 'good design' incorporated clarity of purpose, an economy of material, and a 
delight in use. However, as we have discussed above the breadth of issues to be considered by design today is extensive, not only are the issues broad ranging, but the drivers are complex encompassing political and regulatory perspectives, corporate strategic reasons or indeed the moral, philosophical and ethic perspectives of individuals.

Furthermore, as we have moved into a world dominated by both physical and digital products and services, 'good design', must also increasingly address moral and ethical issues, especially around the privacy, trust and security attributes afforded or otherwise by digital products and services Thus, today truly good design needs to meet not only clients' requirements but also those of our current and future society. In brief, 'good design' has extended beyond environmental compliance and user centred design to a consideration of broader social issues and human challenges facing all nations, such as healthy living, mental health, digital inclusivity, demographic change, climate change, cultural diversity, and social policy.

The question is what are the principles of good design going forward and should they cover every domain or is it necessary that they are prescriptive? For example, how far do such principles need to extend to cover designing for digital health.

\section{Digital Health Challenges}

This is the next challenge for designers. Now that we have experienced a major global pandemic, we have looked at ways of living that have reduced pollution and use of natural resources, yet we have poor global health and declining wellbeing. How do we reframe the role of design for digital health globally to catch up on these and to act with total responsibility for the future of humans and the planet? In this section we consider issues related to the challenges of digital health design.

\subsection{Dehumanisation of healthcare}

The introduction of electronic medical records has "degraded relationships between clinicians and our patients" (Fiske et al, 2020) and contributed to the corporatization of health care. Patients spent on average ten minutes with a medical professional, with doctors have to spend more time dealing with our medical forms than talking with the patient (Jacobs et al, 2017). In a medical environment people can feel like an object being pushed along a conveyor belt, and at each stop stress gets repeated (Buetow, 2016). It is often unavoidable that a series of tests must be run or that different people are going to ask you the same question.

This may increase confusion, stress and anxiety, as several studies have reported that anticipating a stressful situation can increase stress in people, causing similar effects to those of who actually experience it (Von Dawans et al, 2012; Brosschot et al, 2016; Neubauer et al, 2018). The fear of the unknown and relinquishing control when one enters a hospital, along with the depersonalisation of the healthcare service provision (by healthcare staff who see often too many patients at a time) form key challenges. Thus, the shift to digital healthcare could lead to a dehumanization and depersonalization of healthcare, affecting significantly the relationship between health professionals and people (Ricciardi \& Boccia, 2017). 


\subsection{Responsibility shift: from state to person}

The shift from patient-centred to person-centric healthcare is now evident in the literature and has been accelerated due to information access and personal health monitoring (Eaton et al., 2015; McCormack et al, 2017; Britten et al, 2020). This, followed by the high financial healthcare costs associated with the management of chronic diseases has led to the emergence of self-management healthcare (Pulvirenti et al, 2014). A shift of healthcare services from hospitals into people's homes and the community. Although, on one hand, it can help empower individuals to take more control of their healthcare provision, one should question that the motivations behind this shift are not necessarily based on what is best for the individual person, but on the financial burden to healthcare systems (Liddy et al, 2014; Russell et al, 2018). Furthermore, managing one's condition through selfmanagement requires digital skills, the relevant know-how and resources to do so effectively (Moore et al, 2017; Russell et al, 2018). Without appropriate training people, especially from the most vulnerable socio-economic groups (who are at higher risk of developing chronic health conditions) would be left at their own mercy.

\subsection{Health Inequality, digital divide, gender equality}

In recent years, researchers have reported that social inequalities in health arise because of inequalities in the way people live on a day-to-day basis, encouraging the development of disease and unhealthy behaviours (Woodward \& Kawachi, 2002; Marmot, 2013). Also, the environment where one lives and spends most of their time (i.e. at home/work/school, etc) play a major role in creating or maintaining health inequalities (Kawachi et al, 2002; Ghani et al, 2021). There are significant inequalities in health not only within but also between countries as well (Marmot, 2005).

Apart from socio-economic factors, health inequalities are also affected by gender inequalities (Read \& Gorman, 2010; Ghani et al, 2021) as well as racial and ethnic inequalities (Lopez et al, 2011; Mitchell, 2019) especially in South Africa, the UK and the USA (Gwatkin, 2000; Evandrou et al, 2016).

Although digital health systems are increasingly becoming part of the healthcare provision globally, still large parts of populations, especially in the Global South lack access to the Internet (Graham, 2014) with mobile phones being often the only means of connecting to the Internet (Makri, 2019). As Makri (2019) notes "digital is fundamentally an amplifier, which it can either be used to exacerbate health disparities or to bridge and support increasing progress towards health equity".

Moreover, another inequality is being created by the digital divide between the young and the old. With older people being less likely to use the Internet and other digital technologies, so is the potential to benefit from the use of health/mHealth apps, excluding them from accessing digital health services (Gitlow, 2014). This forms another barrier for seniors and minority groups, widening further the divide (Neter \& Brainin, 2012). Looking at emerging digital health innovations, such as precision medicine, exclusion from digital healthcare provision would, in the not-so-distant future, have a great impact on people's health and wellbeing (Neter \& Brainin, 2012; Makri, 2019).

\subsection{Current and emerging technology}

Digital healthcare technologies provide a growing field in healthcare, holding potentially transformative promise and experiencing a surge in diffusion. Nevertheless, there are also several significant challenges and impacts on individuals as well as healthcare systems across the world. 
Below we explore in more detail several emerging digital healthcare technologies and pose questions in terms of social responsibility design.

The advances in digital healthcare and biomedical technologies along with the demographic shift in life expectancy in later years, could impact further the resources required by healthcare systems (Ricciardi, \& Boccia, 2017). The specific problems with mobile health (mHealth) and Internet of Things (IOT) include data sharing and consent management, privacy and user trust (Majumder et al, 2017). For example, the wider use of loT within healthcare within the home, could threaten privacy, as people could be identified by data shared from loT devices (Ricciardi, \& Boccia, 2017). According to Al Ameen et al (2012) in McGhin et al (2019:66) they could invite questions such as: "can healthcare data be gained from the individual, such as a heart rate monitor, without the consent of the person in an emergency setting?". Despite the progress in terms of technology maturity and development in mHealth and IoT, individual user preferences and application beneficiaries are still often excluded from the design process. Often an afterthought when the digital health products and services are at the evaluation stage (Majumder et al, 2017).

In parallel with the emergence of the loT, Artificial Intelligence (AI) forms another set of potentially disruptive technologies in the field of healthcare. On the one hand, Al healthcare applications are seen as a toolset for increasing efficiency and effectiveness, by automating certain repetitive tasks; and in doing so releasing healthcare professionals from demanding cognitive tasks such as searching medical records, etc. On the other hand, they are seen as having significant threats to the jobs of doctors, nurses, managers replaced by automation, as well as contributing to the ethical and privacy issues (Sun \& Medaglia, 2019) discussed above. While the adoption of Al in health has been slow, its use partly is on the increase. This is because of the human resources cost savings they offer in the key component of healthcare service provision by replacing face-to-face interactions (Jung \& Padman, 2015). Thus, the use of Al could potentially lead to the redesign of the healthcare service delivery. Although, increasing treatment efficiency, empowering self-care and decreasing medical errors from fatigue are all positives; significant concerns remain. With a digital healthcare already becoming dehumanised (as discussed above), reducing human and face-to-face interactions threatens to exacerbate this even further.

3D bioprinting could assist in the field of personalised medicine by spearheading the development of bespoke organs and tissues (Gilbert et al, 2018; Chameettachal et al, 2019). It could accelerate the digital healthcare revolution, as it enables the remote fabrication of drug delivery systems, enabling greater control over the bioavailability of medications. This would make possible the tailoring of medicines to the needs of individual patients (Awad et al, 2018; Vijayavenkataraman et al, 2018). Despite, 3D bioprinting remaining a potentially viable solution for assisting with the organ transplantation scarcity (Chameettachal et al, 2019) and creating alternatives to animal testing (Vermeulen et al, 2017), there are several important ethical and regulatory concerns that need to be addressed (Gilbert et al, 2018). These ethical concerns have to be adequately addressed for successful market translation of this technology (Vijayavenkataraman et al, 2018). An ethical concern, which applies to all new and expensive technoscientific solutions (such as bioprinting, as well as the ones discussed above), is that they are likely to benefit only a privileged minority. Meaning that access to scientific benefits could be substantially unequal, creating social healthcare stratification (Vermeulen et al, 2017).

These are, just a selection of emerging challenges faced by designers by the onset of digital health technologies. It provides us with a baseline to consider principles for good design in this context. 


\section{Ten Principles of Socially Responsible Digital Health Design}

Following from the challenges presented above and the discussion on the evolution of design, we posit that there is a need for principles of socially responsible digital health design as good design. Talking an approach similar to Dieter Ram's ten principles of good design we present below the ten principles of socially responsible digital health design as good design because, Good Digital Health Design:

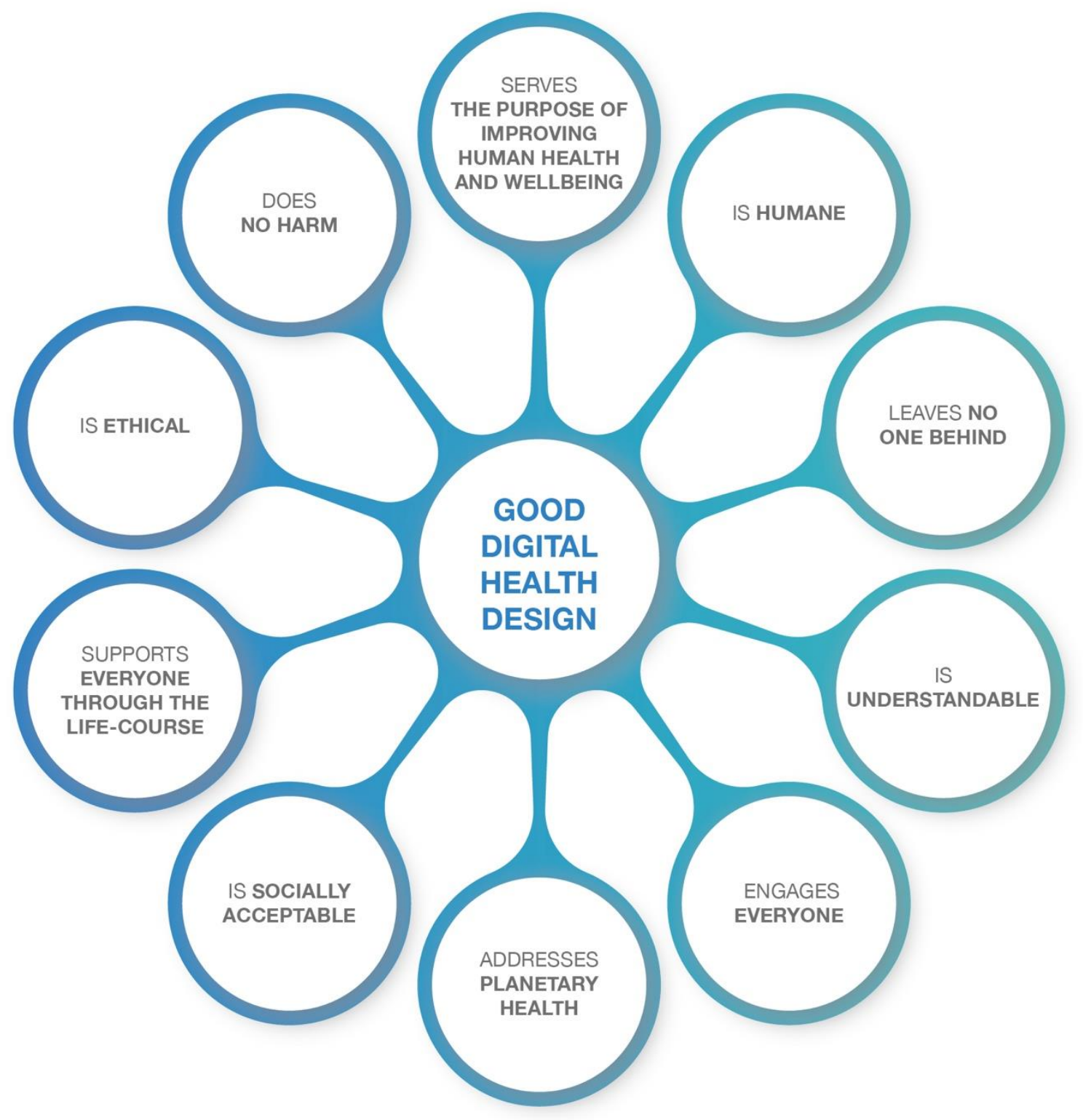

Figure 2: Ten Principles of Socially Responsible Digital Health Design

\section{1 serves the purpose of improving human health and wellbeing}

Its first and foremost goal is to keep us healthy. It is designed to be proactive rather than reactive. To help us practice lifelong wellness. It does not wait for us to develop some sign of an illness to then treat us. Good digital health design becomes active, catering for our physical but also mental wellbeing in all its applications. It helps us consciously remain in a state of wellbeing. It is empowering helping us becoming our own 'Placebo' (positive belief in being healthy). 


\section{2 is humane}

It recognises the value of the human in the healthcare system, appreciating people as individuals. Good design places individuals at the heart of the healthcare provision, ensuring that digital health serves as a tool that frees medical professionals to spend more time with their patients. It also, does not alienate people, it makes them feel fulling part of the digital healthcare service provision, and provides a new paradigm that humanises digital health and our interaction with it.

\section{3 leaves no one behind}

It supports the reduction of health inequalities and ensures no one is left behind. It ensures equal access and inclusion especially of the most vulnerable members in our society. Good digital health design recognises and tries to reduce socioeconomic inequalities that result in health inequalities, recognising and valuing the plurality and cultural values of different societies and groups.

\section{4 is understandable}

It is easy to access and understand how to use and it aims for eHealth literacy. It is designed to be easily accessible and understandable by at-risk and the most vulnerable eHealth literate groups. Good digital health design helps us achieve better health literacy. It becomes a personal advocate of people representing the person's interests in medical situations.

\section{5 engages everyone}

It engages all beneficiaries and stakeholders in the digital health design process and 'design discourse'. Good digital design adopts a One Health approach. It works together with multiple sectors and stakeholders to achieve better public health, at local, regional, national, and global levels.

\section{6 addresses planetary health}

It cares for the state and health of our planet as a means of protecting our own health. Good digital design safeguards human health by safeguarding the environment and its resources. It protects the health of human civilisation and the environment it flourishes in, by balancing human needs with the preservation of the Earth to sustain the health and wellbeing of future generations.

\section{7 is socially acceptable}

It avoids using anything which further increases digital health users' differences. Good digital health design does not call attention to a person's disability or ill-health generating a societal stigma. It ensures that its physical design, morphology, behaviour, and functionality of digital health products and services enhance its adoption and use. It appreciates the role of the family of the digital health user, and society overall in influencing its acceptability, adoption and use.

\section{8 supports everyone through the life-course}

It recognises that the need to support health and wellbeing across our life-course and that lifelong wellness, begins as early as childhood and should be promoted though out our life. It extends not just our years of living but ensuring that these are healthy too. It supports us in all aspects of our lifecourse, from 'womb to tomb'. 


\section{9 is ethical}

It considers the environmental, societal, ethical, legal and economic issues of current and emerging technological innovations. Good digital health design provides a balance between the individual as the owner of data and data use, patient identification and confidentiality, data sharing and management. It embeds ethics and data protection by design and by default.

\subsection{0 does no harm}

It focuses on helping us undo old unhealthy habits we need to abandon; and reinforces only positive healthy habits, avoiding by design anything that would impact our health negatively, both explicitly but also implicitly.

\section{Conclusion}

The opportunities afforded by digital health technologies are undoubtedly significant and there is no end to what they can do to extend both life expectancy but also the quality of life. However, there is variability of how such technologies are accessed globally and also how they impact upon people's life. The role design and designers can take in the development and implementation of such technologies has to be one of a socially responsible stance. Good design in this realm can be no other than socially responsible, and therefore applying the ten principles (Figure 2 ) is critical to ensure all human beings and the planet benefit from the technologies available to us.

\section{References}

Awad, A., Trenfield, S. J., Gaisford, S., \& Basit, A. W. (2018). 3D printed medicines: A new branch of digital healthcare. International journal of pharmaceutics, 548(1), 586-596.

Britten, N., Ekman, I., Naldemirci, Ö., Javinger, M., Hedman, H., \& Wolf, A. (2020). Learning from Gothenburg model of person centred healthcare. bmj, 370 .

Brosschot, J. F., Verkuil, B., \& Thayer, J. F. (2016). The default response to uncertainty and the importance of perceived safety in anxiety and stress: An evolution-theoretical perspective. Journal of Anxiety Disorders, 41, 22-34.

Buckminster Fuller, R. (1963) World Design Science Decade Phase 1 Document 1, Estate of Buckminster Fuller, Google Books

Buetow, S. (2016). Person-centred health care: balancing the welfare of clinicians and patients. Routledge.

Chameettachal, S., Yeleswarapu, S., Sasikumar, S., Shukla, P., Hibare, P., Bera, A. K., ... \& Pati, F. (2019). 3D Bioprinting: Recent Trends and Challenges. Journal of the Indian Institute of Science, 99(3), 375-403.

Chen, D. S., Cheng, L. L., Hummels, C. C. M., \& Koskinen, I. (2016). Social design: an introduction. International Journal of Design, 10(1), 1-5.

Cooper, R., (2005). Ethics and altruism: what constitutes socially responsible design? DesignManagement Review, 16 (3), 10-18.

Cooper, R., Boyko, C. T., \& Cooper, C. (2011). Design for health: the relationship between design and noncommunicable diseases. Journal of health communication, 16(sup2), 134-157.

Cooper, R., (2019) Design research - Its 50-year transformation Design Studies. 65, 6-17. 
Eaton, S., Roberts, S. and Turner, B., (2015). Delivering person centred care in long term conditions. BMJ, 350, p.h181.

Evandrou, M., Falkingham, J., Feng, Z., \& Vlachantoni, A. (2016). Ethnic inequalities in limiting health and self-reported health in later life revisited. J Epidemiol Community Health, 70(7), 653-662.

Fiske, A., Buyx, A., \& Prainsack, B. (2020). The double-edged sword of digital self-care: Physician perspectives from Northern Germany. Social Science \& Medicine, 260, 113174.

Ghani, F., Tsekleves, E., \& Thomas, Y. F. (2021). Urbanization and Cities as Drivers of Global Health. In I. Kickbusch, D. Ganten, \& M. Moeti (Eds.), Handbook of Global Health (pp. 1-28). Springer International

Gilbert, F., O'Connell, C. D., Mladenovska, T., \& Dodds, S. (2018). Print me an organ? Ethical and regulatory issues emerging from 3D bioprinting in medicine. Science and engineering ethics, 24(1), 73-91.

Gillon, R. (1994). Medical ethics: four principles plus attention to scope. British Medical Journal, 309(6948), 184.

Gitlow, L. (2014). Technology use by older adults and barriers to using technology. Physical \& Occupational Therapy in Geriatrics, 32(3), 271-280.

Graham, M. (2014). Inequitable distributions in Internet geographies: The global south is gaining access, but lags in local content. Innovations: Technology, Governance, Globalization, 9(3-4), 3-19.

Gwatkin, D. R. (2000). Health inequalities and the health of the poor: what do we know? What can we do?. Bulletin of the world health organization, 78, 3-18.

Jacobs, G., van der Zijpp, T., van Lieshout, F., \& van Dulmen, S. (2017). Research into person-centred healthcare technology: A plea for considering humanization dimensions. Person-Centred Healthcare Research. Oxford: Wiley-Blackwell, 61-68.

Jung, C., \& Padman, R. (2015). Disruptive digital innovation in healthcare delivery: the case for patient portals and online clinical consultations. In The handbook of service innovation (pp. 297318). Springer, London.

Kawachi, I., Subramanian, S. V., \& Almeida-Filho, N. (2002). A glossary for health inequalities. Journal of Epidemiology \& Community Health, 56(9), 647-652.

Majumder, S., Mondal, T., \& Deen, M. J. (2017). Wearable sensors for remote health monitoring. Sensors, 17(1), 130.

Makri, A. (2019). Bridging the digital divide in health care. The Lancet Digital Health, 1(5), e204-e205.

Marmot, M. (2005). Social determinants of health inequalities. The lancet, 365(9464), 1099-1104.

Marmot, M. (2013). Health inequalities in the EU. Final report of a consortium. European Commission Directorate-General for Health and Consumers. https://ec.europa.eu/health//sites/health/files/social_determinants/docs/healthinequalitiesineu_ 2013_en.pdf

McGhin, T., Choo, K. K. R., Liu, C. Z., \& He, D. (2019). Blockchain in healthcare applications: Research challenges and opportunities. Journal of Network and Computer Applications, 135, 62-75.

Mitchell, U. A., Chebli, P. G., Ruggiero, L., \& Muramatsu, N. (2019). The digital divide in health-related technology use: The significance of race/ethnicity. The Gerontologist, 59(1), 6-14.

Moore, L., Britten, N., Lydahl, D., Naldemirci, Ö., Elam, M., \& Wolf, A. (2017). Barriers and facilitators to the implementation of person - centred care in different healthcare contexts. Scandinavian journal of caring sciences, 31(4), 662-673.

McCormack, B., van Dulmen, S., Eide, H., Skovdahl, K., \& Eide, T. (Eds.). (2017). Person-centred healthcare research. John Wiley \& Sons.

Neter, E., \& Brainin, E. (2012). eHealth literacy: extending the digital divide to the realm of health information. Journal of medical Internet research, 14(1), e19. 
Neubauer, A. B., Smyth, J. M., \& Sliwinski, M. J. (2018). When you see it coming: Stressor anticipation modulates stress effects on negative affect. Emotion, 18(3), 342.

Liddy, C., Blazkho, V., \& Mill, K. (2014). Challenges of self-management when living with multiple chronic conditions: systematic review of the qualitative literature. Canadian Family Physician, 60(12), 1123-1133.

López, L., Green, A. R., Tan-McGrory, A., King, R. S., \& Betancourt, J. R. (2011). Bridging the digital divide in health care: the role of health information technology in addressing racial and ethnic disparities. The Joint Commission Journal on Quality and Patient Safety, 37(10), 437-445.

Papanek, V (1971) Design for the Real World : Human Ecology and Social Change. New York, Pantheon Books

Pulvirenti, M., McMillan, J., \& Lawn, S. (2014). Empowerment, patient centred care and self management. Health Expectations, 17(3), 303-310.

Rams, D. (2009). Dieter Rams: ten principles for good design. From Vitsoe.com: https://www.vitsoe.com/gb/about/good-design

Read, J. N. G., \& Gorman, B. K. (2010). Gender and health inequality. Annual Review of Sociology, 36, 371-386.

Ricciardi, W., \& Boccia, S. (2017). New challenges of public health: bringing the future of personalised healthcare into focus. European journal of public health, 27(suppl_4), 36-39.

Russell, S., Ogunbayo, O. J., Newham, J. J., Heslop-Marshall, K., Netts, P., Hanratty, B., ... \& Kaner, E. (2018). Qualitative systematic review of barriers and facilitators to self-management of chronic obstructive pulmonary disease: views of patients and healthcare professionals. NPJ primary care respiratory medicine, 28(1), 1-13.

Sun, T. Q., \& Medaglia, R. (2019). Mapping the challenges of Artificial Intelligence in the public sector: Evidence from public healthcare. Government Information Quarterly, 36(2), 368-383.

Tsekleves, E. and Cooper, C. (Eds.) (2017). Design for Health. (Design for Social Responsibility). London: Routledge.

Tsekleves, E., Cooper, R., \& Spenser, J. (Eds.) (2021). Design for Global Challenges and Goals. (Design for Social Responsibility). Routledge.

Vermeulen, N., Haddow, G., Seymour, T., Faulkner-Jones, A., \& Shu, W. (2017). 3D bioprint me: a socioethical view of bioprinting human organs and tissues. Journal of Medical Ethics, 43(9), 618624.

Vijayavenkataraman, S., Yan, W. C., Lu, W. F., Wang, C. H., \& Fuh, J. Y. H. (2018). 3D bioprinting of tissues and organs for regenerative medicine. Advanced drug delivery reviews, 132, 296-332.

Von Dawans, B., Fischbacher, U., Kirschbaum, C., Fehr, E., \& Heinrichs, M. (2012). The social dimension of stress reactivity: acute stress increases prosocial behavior in humans. Psychological science, 23(6), 651-660.

Woodward, A., \& Kawachi, I. (2000). Why reduce health inequalities?. Journal of Epidemiology \& Community Health, 54(12), 923-929.

Author Bios:

Dr Emmanuel Tsekleves is a Senior Lecturer in design for health and Co-Director of the Future Cities Research Institute at Lancaster University. He is the convenor of the Design Research Society Global Health special interest group. His research focuses on tackling community health challenges across the world. 
Prof Rachel Cooper OBE is Distinguished Professor of Design Management and Policy at ImaginationLancaster, at Lancaster University. Her research interests cover: design thinking; design management; design policy; and across all sectors of industry, a specific interest in design for wellbeing and socially responsible design. 